\title{
Foregut Cyst in Heart: Case Report
}

\author{
Naresh Kumar Aggarwal' ${ }^{1}$ Sushanta Kumar Bhoi ${ }^{1}$ \\ ${ }^{1}$ Department of Cardiac Anaesthesiology, Manipal Hospitals, \\ Dwarka, New Delhi, India \\ 2Department of Cardiac Surgery, Manipal Hospitals, Dwarka, \\ New Delhi, India
}

\author{
Y. K. Mishra²
}

\begin{abstract}
Address for correspondence Naresh Kumar Aggarwal, MD, Department of Cardiac Anaesthesiology, Manipal Hospitals, Sector 6, Dwarka, New Delhi 110075, India (e-mail: drnaresh15@gmail.com).
\end{abstract}

\begin{abstract}
Keywords

- foregut cyst

- left ventricle

- transannular decompression

A 70-year-old female presented with gradual onset of dyspnea with moderate exertion for 6 months. She had a history of stroke 1 month back which was resolved. On two-dimensional echo, she had a mass in left atrium $(1.6 \times 1.6 \mathrm{~cm})$ with base attached to interatrial septum adjacent to anterior mitral leaflet. On coronary angiography, she had lesion in left anterior descending coronary artery (LAD) with 60 to $70 \%$ stenosis. But intraoperative transesophageal echocardiography revealed mass in left ventricle attached to posterior mitral leaflet undersurface. The operation was performed; coronary artery bypass graft surgery with left internal mammary artery to LAD grafting and transannular decompression of the left ventricular mass was performed. Surgery was done uneventfully. The cyst content consisted of necrotic sebaceous-type material with calcification. Histopathology of excised material revealed it to be a foregut cyst of myocardium. The patient had an uneventful postoperative course and was discharged in good clinical condition.
\end{abstract}

\section{Introduction}

Foregut cysts have been described in a variety of locations in the mediastinum. They arise from embryonic remnants of the primitive foregut and include bronchogenic cysts arising from the ventral foregut and enterogenous cysts arising from the dorsal foregut. The foregut cyst, which is a general term encompasses bronchogenic, esophageal, gastric, or enteric cysts. Intracardiac foregut cysts can be diagnosed with transthoracic echocardiography as a space-occupying lesion with compressive effects, hence, the reduction in cardiac function or blood flow obstruction. Majority of these cysts are managed with early surgical resection (1) to obtain tissue diagnosis and (2) to prevent complications related to their enlargement.

\section{Case Report}

A 70-year-old female presented with gradual onset of dyspnea with moderate exertion for 6 months. She had history of stroke 1 month back which was resolved with no neurologic deficit at present. She was a known case of type 2

\section{published online} October 8, 2020
DOI https://doi.org/ $10.1055 / \mathrm{s}-0040-1716636$ ISSN 2457-0206. diabetes mellitus. She was evaluated in our hospital. All blood investigations were within normal limits. Coronary angiography showed single vessel disease of left anterior descending coronary artery with 60 to $70 \%$ stenosis. On carotid Doppler she had bilateral carotid disease (30-40\% stenosis), but, magnetic resonance angiography of neck vessels showed normal course and caliber. MRI of brain showed subacute chronic infarct in right fronto-temporoparietal region.

Two-dimensional echo revealed ejection fraction of $60 \%$ moderate left ventricular hypertrophy, aortic leaflets were thickened and calcified. There is a mass in left atrium $(1.6 \times 1.6 \mathrm{~cm})$ with its base attached to interatrial septum adjacent to anterior mitral leaflet base suggesting left atrium (LA) myxoma. Traces of mitral regurgitation, mitral annular calcification were present.

Patient was planned for coronary artery bypass graft surgery and LA myxoma removal. Intraoperatively we did transesophageal echocardiography to confirm diagnosis and locate and measure the size of mass. We found the mass in left ventricle which was attached to the base of posterior mitral leaflet. Mass seen was cystic in appearance (-Figs. 1-3).
(C) 2020. Official Publication of The Simulation Society (TSS), accredited by International Society of Cardiovascular Ultrasound (ISCU).

This is an open access article published by Thieme under the terms of the Creative Commons Attribution-NonDerivative-NonCommercial-License, permitting copying and reproduction so long as the original work is given appropriate credit. Contents may not be used for commercial purposes, or adapted, remixed, transformed or built upon. (https://creativecommons.org/licenses/by-nc-nd/4.0/) Thieme Medical and Scientific Publishers Pvt. Ltd., A-12, 2nd Floor, Sector 2, Noida-201301 UP, India 


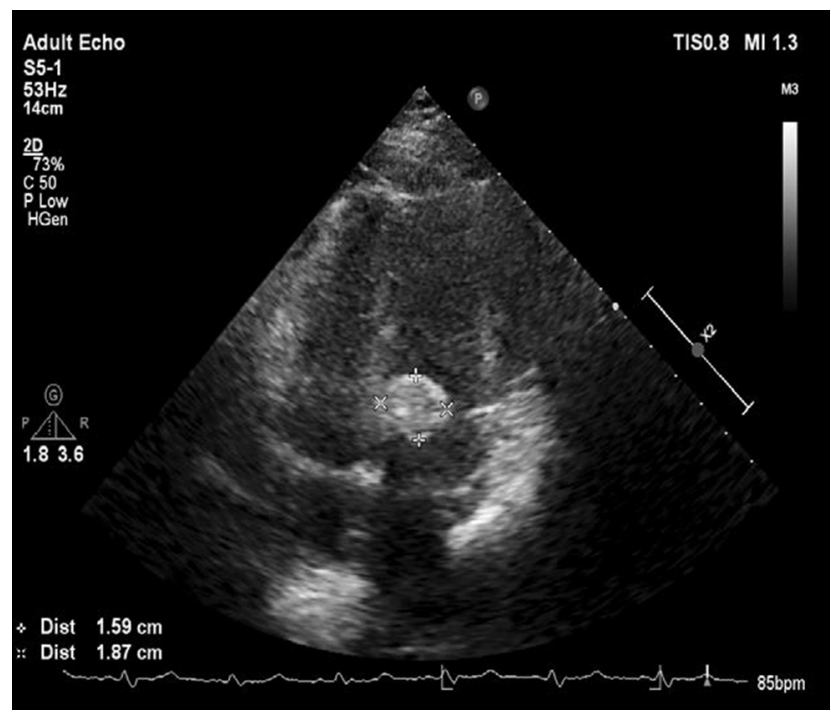

Fig. 1 Two-dimensional echo apical 4C view. 4C, four chamber.

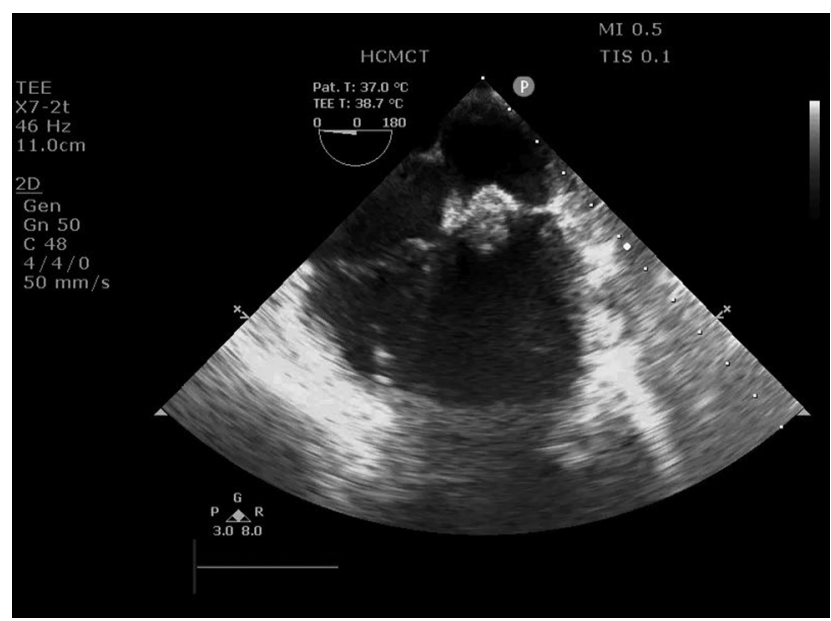

Fig. 2 TEE view midesophageal $4 \mathrm{C}$ view showing a mass underneath the mitral valve. 4C, four chamber; TEE, transesophageal echocardiography.

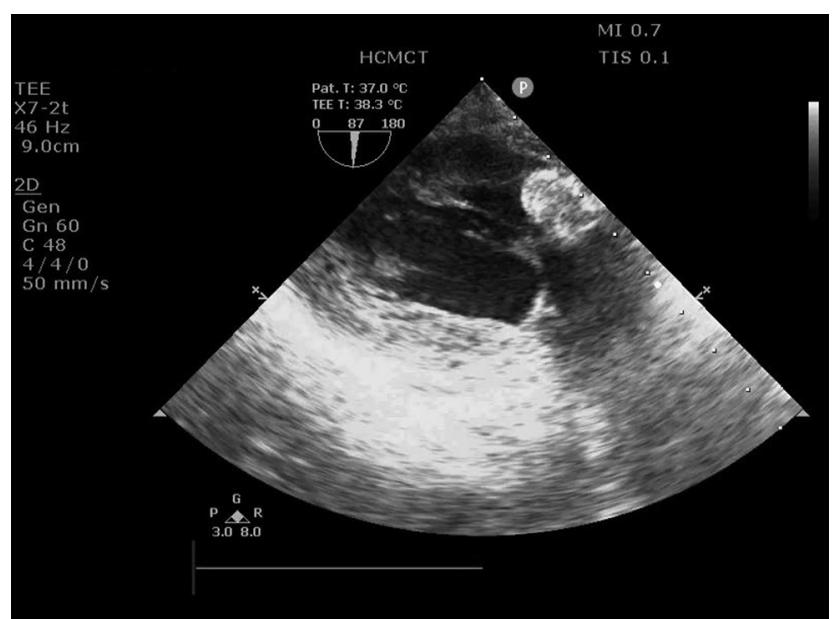

Fig. 3 TEE transgastric $2 C$ view showing a mass under the posterior mitral leaflet. 2C, two chamber; TEE, transesophageal echocardiography.
An attempt to take a biopsy sample of the mass resulted in extrusion of the cyst contents, which consisted of necrotic material which had a pasty yellowish-gray appearance. The contents were evacuated, and the cyst wall was closed from within the left ventricle. There was no plane of dissection that would allow removal of the cyst. After completion of the coronary bypass grafting and decompression of cyst, the heart was separated from cardiopulmonary bypass satisfactorily. Histopathological study of the excised material revealed it to be foregut cyst of myocardium.

\section{Discussion}

Cysts of the myocardium are very uncommon. When they occur, they are most commonly hydatid cysts. Myocardial involvement occurs in less than $2 \%$ of the hydatid disease. ${ }^{1}$ Hydatid cysts in the heart usually shell out from the surrounding myocardium relatively easily. Although a positive histologic diagnosis could not be done in either of these cases, the findings are typical to degenerate foregut cysts. In this case, the cyst wall was fibrous and calcified with no epithelial lining identified. The cyst contained necrotic sebaceous-type material with calcification. ${ }^{2}$ Foregut cysts more commonly occur in the mediastinum where the natural history is one of enlargement and compression of surrounding structures due to infection, epithelial secretions, or bleeding. Two-thirds of the patients eventually develop symptoms due to airway obstruction.

In a series of 444 adult autopsies with a primary tumor or cyst of the heart or pericardium, six patients had an intramyocardial bronchogenic cyst. ${ }^{3}$ These were the only intramyocardial cysts; they were 1 to $2 \mathrm{~cm}$ in diameter and were incidental findings. One of the six cysts crossed the posterior atrioventricular groove as in our patient. In the same series, there were 80 simple pericardial cysts and 118 myxomas. Shelling out of these rare foregut cysts may not be possible because the cyst wall may degenerate to a thin, fibrous capsule intimate with the adjacent myocardium. The size of the cyst may also preclude cyst removal due to disruption of ventricular or valve function, depending on the location. In this circumstance, decompression by drainage may be the most judicious management.

Intracardiac foregut cysts can be diagnosed with transthoracic echocardiography as a space-occupying lesion with compressive effects, hence, the reduction in cardiac function or blood flow obstruction. Diagnosis is by histopathology, in which, we see endodermal and mesodermal elements. Teratomas are the main differential diagnosis of foregut cysts, in which, we see ectodermal elements too. ${ }^{4}$

Because these cysts are rare, there is an inclination to obtain a tissue diagnosis at the time of cardiac surgery. There is a reluctance to leave the remnants of cyst communicating with cardiac chamber, and so it is recommended that the cysts be drained into the pericardium. Aggressive evacuation of the contents does not appear to be necessary and may cause bleeding from the cyst wall. The presence of 
radiopaque material within the cyst should distinguish it from other types of cysts so that it is reasonable to make a positive diagnosis without tissue confirmation.

\section{Conflict of Interest}

None declared.

\section{References}

1 Miralles A, Bracamonte L, Pavie A, et al. Cardiac echinococcosis. Surgical treatment and results. J Thorac Cardiovasc Surg 1994;107(1):184-190
2 Strollo DC, Rosado-de-Christenson ML, Jett JR. Primary mediastinal tumors: part II. Tumors of the middle and posterior mediastinum. Chest 1997;112(5):1344-1357

3 McAllister HA, Fenoglio JJ, Tumors of the cardiovascular system. In: Hartman WH, Cowan WR, eds. Atlas of Tumor Pathology. Fascicle 15, Second Series. Washington, DC: Armed Forces Institute of Pathology; 1978:1-64

4 Huang JH, Rudzinski ER, Minette MS, Langley SM. First case of intracardiac foregut cyst occurring in the left-ventricular outflow tract. Pediatr Cardiol 2013;34(8):2060-2062 